\title{
The Misregulation of Cell Adhesion Components during Tumorigenesis: Overview and Commentary
}

\author{
Claudia D. Andl \\ Department of Surgery and Cancer Biology, Vanderbilt University, Nashville, TN 37232, USA \\ Correspondence should be addressed to Claudia D. Andl, claudia.andl@vanderbilt.edu \\ Received 8 July 2010; Revised 23 August 2010; Accepted 10 September 2010 \\ Academic Editor: Ala-Eddin Al Moustafa \\ Copyright ( $) 2010$ Claudia D. Andl. This is an open access article distributed under the Creative Commons Attribution License, \\ which permits unrestricted use, distribution, and reproduction in any medium, provided the original work is properly cited. \\ Cell adhesion complexes facilitate attachment between cells or the binding of cells to the extracellular matrix. The regulation \\ of cell adhesion is an important step in embryonic development and contributes to tissue homeostasis allowing processes such \\ as differentiation and cell migration. Many mechanisms of cancer progression are reminiscent of embryonic development, for \\ example, epithelial-mesenchymal transition, and involve the disruption of cell adhesion and expression changes in components \\ of cell adhesion structures. Tight junctions, adherens junctions, desmosomes, and focal adhesion besides their roles in cell-cell or \\ cell-matrix interaction also possess cell signaling function. Perturbations of such signaling pathways can lead to cancer. This article \\ gives an overview of the common structures of cell adhesion and summarizes the impact of their loss on cancer development and \\ progression with articles highlighted from the present issue.
}

\section{Tight Junctions}

Tight junctions are regulators of the epithelial microenvironment as they are responsible for the formation of paracellular barriers (see Figure 1), [1, 2]. Claudin-based tight junctions and their functions have been analyzed in numerous knockout mouse studies. The loss of claudin-1 or -5 is embryonically lethal due to loss of the barrier function of the skin and loss of the blood-brain barrier $[3,4]$. In cancer, claudins can be found to be up- or downregulated depending on the cancer type. Claudin-1 and -7 are downregulated in esophageal cancer [5], but upregulated in others $[6,7]$. While the mislocalization of claudin-7 in esophageal squamous cell carcinoma leads to the loss of E-cadherin expression, $\mathrm{N}$ glycosylation of E-cadherin has been shown to stabilize tight junctions [8]. An in-depth review of claudins and cancer can be found in this special issue of the Journal of Oncology (Singh et al., [9]).

\section{Desmosomes}

Desmosomes are adhesion complexes tethered to the intermediate filament, (see Figure 1), [10]. Desmosomal cadherins, the desmogleins, establish the contact to the neigh- boring cells [11]. Plakoglobin is homologous to $\beta$-catenin and binds to the same region of the cadherin tail $[12,13]$. While Plakoglobin is highly enriched in desmosomes, it can also be localized to adherens junctions in cells that do not have desmosomes, such as endothelial cells [14, 15]. There is evidence that plakoglobin can participate in Wnt signaling as the transcription factor T-cell factor/lymphoidenhancer factor, TCF-4, contains binding sites for $\beta$-catenin and plakoglobin [16], and that binding of plakoglobin could hinder transcriptional activity. However, Plakoglobin has been shown to have TCF/LEF-dependent transcriptional activity in $\beta$-catenin-deficient cell lines [17].

Desmoplakin connects desmosomes through binding of plakoglobin to the intermediate filament. It is downregulated in oropharyngeal cancer [18] and a target of EGF and progesterone in breast cancer [19]. Interestingly, aside from its obvious function in cell adhesion, desmoplakin has been described to regulate microvascular tube formation [20]. Therefore, desmoplakin may be a novel target for the inhibition of tumor angiogenesis.

The desmosomal cadherins, desmoglein 1 , and 3, are targets in two autoimmune diseases, Pemphigus foliaceus and Pemphigus vulgaris, respectively [21]. Binding of autoantibodies to desmoglein induces cell dissociation and 

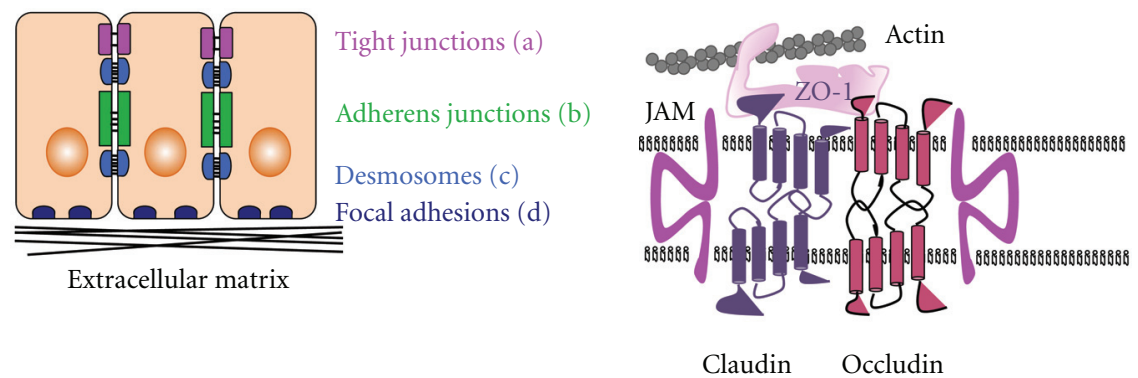

(a)

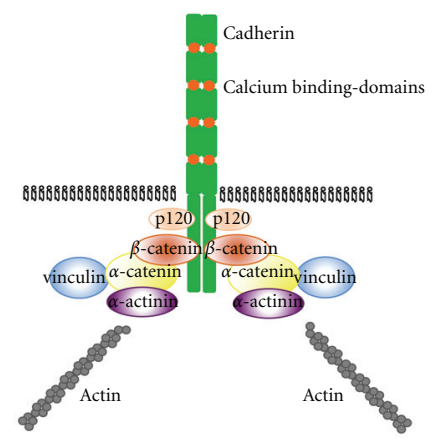

(b)

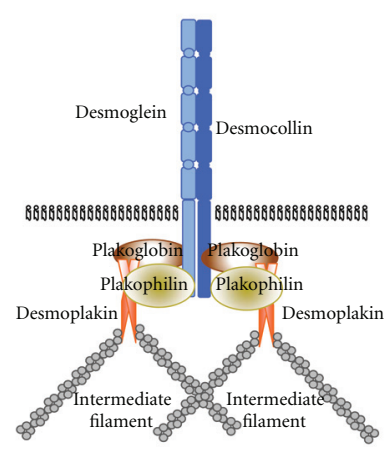

(c)

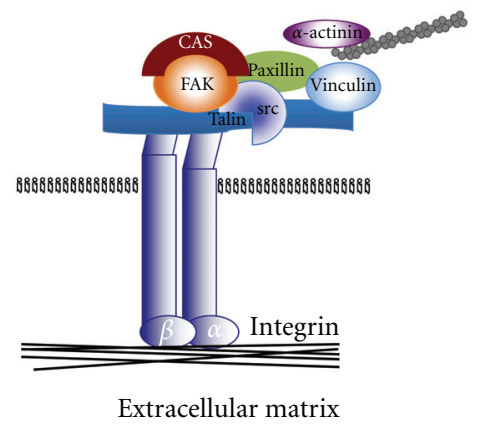

(d)

Figure 1: Schematic diagram of tight junctions (a), adherens junctions (b), desmosomes (c) and focal adhesions (d). This is an overview of the interactions of the major components of cell adhesion complexes.

inhibition of RhoA in a p38 MAPK-dependent pathway causing the hallmark blistering [22]. The implications of desmosomal component loss have been shown in mouse models targeting desmoglein 2 [23] and desmoglein 3 [24, 25], plakoglobin [26] and desmoplakin [27]. Desmoglein 2 knockout mice proved to be embryonically lethal, despite unaffected E-cadherin and $\beta$-catenin expression [23]. Mice with loss of desmoglein 3 presented the same blistering phenotype as Pemphigus patients [24]. Interestingly, targeted loss of desmoplakin in the epidermis allowed the formation of desmosome-like structures, but epithelial sheet formation was impaired in the face of mechanical stress [27].

Effects of desmosomal perturbations on tumorigenesis rarely share the lime light with the well-known consequences of adherens junction loss. However, loss of desmoglein 1 has been associated with poor prognosis in head-and-neck cancer patients [28]. Contrary, Desmoglein 2 upregulation is associated with malignant skin carcinoma including basal cell carcinoma and SCCs in a tissue-microarray-based study [29].

Plakophilins, which are armadillo family members like plakoglobin and $\beta$-catenin, are structural components of the desmosomal plaque and regulate the strength and integrity of cell contacts by facilitating the interaction with the intermediate filament [30]. Decreased expression of plakophilin 1 promotes cell invasion due to desmosome instability [31]. Furthermore, the inverse correlation of plakophilin expression with tumor grade in head-and-neck SCCs has been documented [32]. Similarly, RNAi (small interference RNA) suppression of plakophilin 3 results in transformation of epithelial cells and accelerated tumor formation as well as lung metastasis in mouse tumor xenografts [33].

In addition, other junction types have been identified that use desmosomal components without being desmosomes. A recent review by Pieperhoff et al. [34, 35] highlights composite junctions that connect cardiomyocytes, plakophilin-2-positive junctions in sarcomas as well as the expression of Desmoglein 2 in melanoma. These data together with molecules discussed in the last paragraph of this paper demonstrate that we may not have discovered all types of cell adhesion yet.

\section{Adherens Junctions}

Early on, experiments targeting E-cadherin and $\beta$-catenin have shown that adherens junction components are essential for normal development. E-cadherin- and $\beta$-catenin-null embryos display lethality due to primary defects in morphogenetic events such as trophectoderm development and ectoderm formation $[36,37]$. Deletion of $\mathrm{N}$-cadherin, VEcadherin or plakoglobin also leads to embryonic lethality, however at later stages of development $[26,38,39]$. As for $\alpha-$ catenin, loss of this gene results in death shortly after birth [40]. Interestingly, lack of E-cadherin in thyroid development or adult tissues can be overcome by upregulation of other cadherins as a mechanism of compensation [41, 42]. In cancer, however, loss of E-cadherin is associated with 
tumor progression, even if other cell adhesion complexes remain intact. This has been attributed not only to the detrimental effects E-cadherin loss has on the tissue integrity and dissemination of cells "on the loose", but also to the signaling pathways activated in the absence of E-cadherin [43-45]. Alterations of the cadherin-catenin cell adhesion system and how they relate to cancer have been focus of multiple symposia and meetings resulting in numerous review articles [46] to this date, and where already discussed at the Princess Takamatsu Symposium in 1994 [47-49].

Cadherins interact through their intracellular domain with cytoplasmic proteins, the catenins (see Figure 1), [50, 51]. $\beta$-catenin mediates the anchoring of adherens junctions to $\alpha$-catenin and other actin-binding proteins, and thereby to the cytoskeleton [52]. The relative amount of cadherinbound $\beta$-catenin and free $\beta$-catenin can tip the balance to induce Wnt signaling $[44,53]$. This occurs if free $\beta$-catenin is not degraded by the ubiquitin-proteasome pathway, but translocated to the nucleus instead to regulate target gene expression in conjunction with members of the Tcell factor/lymphoid-enhancer factor (TCF/LEF) family of transcription factors [54]. Activation of cells with Wntmolecules can inhibit $\beta$-catenin degradation and allows its accumulation in the cytosol and translocation to the nucleus leading to the activation of genes such as cyclin D1, cmyc, CD44, and others $[55,56]$. Constitutive active Wnt signaling either through mutations of $\beta$-catenin or loss of adenomatous polyposis coli (APC) function frequently leads to cancer [57], as particularly well understood for colon cancer [58].

p120ctn binds cadherins at the juxtamembrane domain of the cytoplasmic tail and prevents their internalization and degradation $[51,58]$. Similarly to $\beta$-catenin, unbound p120ctn can translocate to the nucleus where it binds Kaiso, a zinc finger transcription factor that acts as a transcriptional repressor and tumor suppressor. Once bound to Kaiso, p120ctn relieves the repressor activity of Kaiso by dissociating it from its sequence-specific binding sites [59]. Wnt signaling stabilizes p120ctn and results in Kaiso withdrawal from the nucleus [60-62]. p120ctn also functions as a regulator of cell motility by modulating the activity of Rho GTPases [63] and has been shown to coordinate Rho inhibition through Rac [64]. In this context, a p120ctn isoform has been shown to fail to inhibit RhoA and to promote invasion [65]. In another model, overexpression of P-cadherin has been linked to the activation of the RhoGTPases, Racl, and Cdc42, through accumulation of p120ctn in the cytoplasm during cell invasion [66]. Furthermore, overexpression of the p120ctn isoform 3A demonstrated cytoplasmic accumulation. This isoform is also associated with cyclin E- and cyclindependent kinase 2-colocalization at the site of centrosomes during mitosis [67]. Ablation of p120ctn in the skin also results in mitotic defects and, additionally, a chronic inflammatory response [68]. Conditional knockout in the small intestine and colon disrupts normal barrier function and epithelial homeostasis resulting in phenotypic and morphological changes associated with inflammatory bowel disease [69].

\section{Cadherins and Cancer Cell Signaling}

Cadherins can signal in different ways: they can bind to growth factor receptors and modulate their internalization and downstream pathways. They also activate signaling mediators, such as phosphatidylinositol 3-kinase (PI3K) or small GTPases. Alternatively, they can recruit transcriptional cofactors, such as $\beta$-catenin or p120ctn, at the cell membrane and thereby negatively control their nuclear translocation.

A number of cadherins has been implicated in cell signaling via interaction with receptor tyrosine kinases: both E-cadherin and N-cadherin interact with FGFR-1. To prevent constitutive or prolonged signaling by FGFR-1, it is sequestered by E-cadherin and internalized [70]. Contrary, complex formation of N-cadherin with FGFR-1 prevents internalization and circumvents degradation. This is known to be one of the mechanisms by which $\mathrm{N}$-cadherin contributes to tumor cell invasion. The switch from E-cadherin to $\mathrm{N}$-cadherin expression occurs during normal developmental processes and is recapitulated in cancer [71, 72].

E-cadherin can also interact with epidermal growth factor receptor (EGFR) [73]. EGFR overexpression is a frequent event in epithelial cancers. EGFR promotes cell motility by phosphorylation of $\beta$-catenin and plakoglobin leading to the disruption of cell adhesion [74]. At the same time, E-cadherin-mediated inhibition of EGFR activity is an important aspect in tumorigenesis. Somatic mutations of E-cadherin have been linked to increased EGFR activation resulting in activation of Ras $[75,76]$. Other studies have found that E-cadherin can cluster EGFR at the cell membrane thereby inhibiting EGFR-mediated signaling [77, 78]. Similarly, desmoglein 1 can suppress EGFR signaling resulting in epidermal differentiation [79].

VE-cadherin is an endothelial specific transmembrane protein concentrated at adherens junctions. Similar to Ecadherin it engages in homophilic cell-cell adhesion. A link to the cytoskeleton is established through the same intercellular partners, $\beta$-catenin, p120 and plakoglobin [80]. Upon VEGF stimulation, VE-cadherin binds to VEGFR-2 preventing vascular endothelial growth factor 2, VEGFR2, phosphorylation. This clustering of VE-cadherin with VEGFR-2 blocks cell proliferation by inhibition of MAPK activation [81]. Furthermore, VE-cadherin is required for $\operatorname{TGF} \beta$ receptor-mediated TGF $\beta$ signaling. This has been demonstrated through knockdown of VE-cadherin [82], but also as $\beta$-catenin null-endothelial cells are unable to respond to TGF $\beta$ stimulation [83].

Another interesting aspect is that tumor-inducing viruses alter cell adhesion. In the case of Kaposi-sarcomaassociated herpesvirus, VE-cadherin is targeted inducing endothelial permeability and contributing to the progression and malignancy of this disease [84]. While Kaposi sarcomaassociated herpesvirus induces VE-cadherin degradation, hepatitis $\mathrm{B}$ virus $\mathrm{HBx}$-protein disrupts adhesion junctions in asrc-dependent manner [85]. Epstein Barr Virus "attacks" cell adhesion complexes through another mechanism: virus-induced gene silencing [86]. E7 protein of Human Papillomavirus 16 (HPV), for example, augments DNA methyltransferase I activity associated with the silencing of 
E-cadherin gene expression [87]. Simultaneously, Ncadherin expression is increased [88]. Augmented cell invasion in HPV-infected cells can be suppressed through restoration of E-cadherin and subsequent downregulation of EGFR [89] or ErbB2 [90]. The mechanism on how Src/ABL regulates cell differentiation and invasion in E6/E7-positive cervical cancer is described in this issue by Yasmeen et al., [91]. Another virus-associated protein, Epstein Barr Viruslatent membrane protein 1 , also affects the cadherin switch [92].

\section{Epithelial Mesenchymal Transition (EMT)}

Similar to the cadherin switch, epithelial-mesenchymal transition is an important process of development, but is "hijacked" as a mechanism of malignant transformation resulting in mesenchymal-like high motility cells. The spotlight on EMT is warranted by the many signaling pathways (peptide growth factors, Src, Ras, Ets, integrins, Wnt/ $\beta$ catenin, and Notch) involved in the regulation of this process. However, a central node is the downregulation of E-cadherin $[93,94]$. Activation of PI3K/Akt is another feature of EMT [95]. Despite its role as a tumor suppressor, TGF $\beta 1$ signaling is often increased in tumor cells and induces EMT, thereby leading to tumor cell invasion [96]. This morphological transition is characterized by extensive changes in the expression of cell adhesion molecules and by a switch from a cytokeratin-rich cytoskeleton to one comprising a mesenchymal cell phenotype, for example, the expression of vimentin and S-100 [97]. The ability of epithelial or carcinoma cells to undergo EMT in culture correlates with cell changes that facilitate invasion and metastasis in vivo [98-100]. Increased cell motility and scattering are caused by a downregulation of E-cadherin, mainly through the TGF $\beta$ induced upregulation of transcriptional repressors such as ZEB1, ZEB2, and Snail. This is accompanied by the decreased expression of ZO-1 and keratins [97, 101, 102].

Focal adhesion kinase (FAK) can also mediate TGF $\beta$ induced EMT [103]. The induction of mesenchymal migration through FAK signaling and its importance in glioblastoma is discussed by Zhong et al. [104] in this issue of the Journal of Oncology. As EMT results in increased cell invasion, it is accompanied by the digestion of the extracellular matrix and changes in matrix metalloproteinase (MMP) expression. Overall, E-cadherin has been shown to induce the suppression of MMP expression. When restored in motile prostate cancer cells, E-cadherin not only reverted EMT and induced an epithelial phenotype, but also reduced MMP-2 expression levels resulting in decreased cell invasion [96, 105]. Lynch et al. [106] describe in this issue how cleavage of E-cadherin by MMP-7 promotes cell proliferation through activation of RhoA.

The microenvironment is a prominent modulator of tumorigenesis and some of these aspects are covered in this special issue: the modeling of microenvironments in vitro (by Ngalim et al. [107]), the tumor-stromal interactions in prostate cancer (by Josson et al. [108]) and the upregulation of laminin-322 by lysophosphatic acid and its effects on colony dispersal (by Yamashita et al. [109]).
More recently, with the advent of microRNAs, small noncoding RNAs (miRNAs) regulating gene expression, an additional level ofprotein translation regulation has been added. A number of miRNAs that inhibit tumor suppressor genes have been identified as well as miRNAs, which negatively affect the translation of oncogenes. Cadherin scan be targets of miRNAs directly or indirectly through the modulation of transcriptional repressors that target cadherins. Ma et al., identified E-cadherin as a direct target of miR-9 [110] leading to activation of $\beta$-catenin and increased invasion as well as increased tumor angiogenesis via VEGF upregulation. miR145 is an example of a tumor suppressor miRNA, which silences MUC-1, thereby reducing $\beta$-catenin and oncogenic cadherin-11 [111]. The miR-200 family gained a lot of attention as it participates in a signaling network with the E-cadherin repressors, ZEB1 and 2 and TGF $\beta 1$, therefore placing it at the center for the regulation of the epithelial phenotype. Another central regulator of cell invasion and metastasis that is upregulated in the absence of E-cadherinis Twist [43]. Twist, as well as ZEB1 and other transcription factors, is thought to induce EMT by suppression of Ecadherin. The data by Onder et al. [43], however, suggest Twist to be downstream of E-cadherin and sufficient to mediate cell invasion and metastasis as well as to prevent anoikis. The authors demonstrated that, while the loss of cellcell contacts can induce changes in gene expression leading to increased cell invasion, the induction of EMT and its associated gene expression changes only occurs if $\beta$-catenin is released from the E-cadherin cytoplasmic tail.

\section{Focal Adhesions}

FAK, focal adhesion kinase, is a crucial mediator of integrin and growth factor signaling. FAK resides within focal adhesion complexes, large integrin clusters that mediate crosstalk between the extracellular matrix and the cytoskeleton, where it regulates outside-in signaling (see Figure 1). High levels of FAK in a variety of human cancers have been reported $[112,113]$, including a study in head and neck squamous cell carcinoma (HNSCC) that shows enhanced FAK signaling at the onset and progression of HNSCC [114]. The increased expression of FAK has been linked to cancer cell migration, proliferation, and survival $[115,116]$. Motility defects in FAK-null ES cells [117] can be restored with wild-type FAK, but not with a mutant of FAK lacking the $\mathrm{Ty}^{397}$-phosphorylation site, which is responsible for Src recruitment [118]. Actin rearrangements are responsible for the formation of adhesion complexes that stabilize the leading edge. Leading edge formation and membrane ruffles are regulated by Rho GTPases such as Rac 1 and RhoA [119]. This issue of Journal of Oncology also features paper focusing on the effects of hyperphosphorylated FAK on its localization to focal adhesions (see Hamadi et al. [120]). Two FAK-binding scaffold proteins that mediate Racl activity are CAS (p130cas) and paxillin. Paxillin regulates the localization of FAK [121] and possibly regulates Rac1. Interestingly, in the study by Yano et al. [121] the suppression of FAK and paxillin resulted in increased cell migration, presenting FAK as a negative regulator of cell motility in contrast to other 
reports. Furthermore, the impaired FAK/paxillin signaling cascade prevented $\mathrm{N}$-cadherin-based cell-cell contacts. While E-cadherin has been described to stimulate Racl activity [122], N-cadherin is thought to suppress Racl activation [123]. The important role of FAK in cancer is supported by the intersection of the FAK and p53 signaling pathways. Not only has the FAK-promoter p53 binding sites, there is also a high correlation between FAK upregulation and p53 mutations [124]. These data demonstrate the regulation of FAK by $\mathrm{p} 53$.

\section{Summary}

While the main components of cell adhesion structures are well defined, recently new players such as the nectins have been identified [125]. Similar to cadherins, nectins bind the cytoplasmic protein afadin and are linked to the actin cytoskeleton [126]. However, nectins can participate in cell adhesion through interaction with cadherins in adherens junctions, ZO-1 or claudins in tight junctions as well as independently [127-129]. Additionally, nectins have been shown to regulate E-cadherin endocytosis [130-132] and to function in migration and polarization [133]. Others include abLIM3, a novel component of adherens junctions [134], and protocadherins, which have multiple functions including neuronal specificity $[135,136]$ and are therefore not discussed in this issue. Differences in the function and tissue-specific expression patterns of all the cell adhesion molecule family members involved in the pathogenesis of cell transformation make therapeutics challenging. However, knowledge of the crosstalk between signaling pathways and common themes such as the interaction of cell adhesion molecules with growth factor receptors allow new scientific advances. Taken together, new mechanisms of the regulation of cell adhesion structures and their signaling function demonstrate the importance of understanding cell adhesion and its impact on disease (see Cell Junctions, edited by LaFlamme [137]) and tumorigenesis [138].

\section{References}

[1] A. Hartsock and W. J. Nelson, "Adherens and tight junctions: structure, function and connections to the actin cytoskeleton," Biochimica et Biophysica Acta, vol. 1778, no. 3, pp. 660669, 2008.

[2] A. Tamura, Y. Kitano, M. Hata et al., "Megaintestine in claudin-15-deficient mice," Gastroenterology, vol. 134, no. 2, pp. 523-534, 2008.

[3] M. Furuse, M. Hata, K. Furuse et al., "Claudin-based tight junctions are crucial for the mammalian epidermal barrier: a lesson from claudin-1-deficient mice," Journal of Cell Biology, vol. 156, no. 6, pp. 1099-1111, 2002.

[4] T. Nitta, M. Hata, S. Gotoh et al., "Size-selective loosening of the blood-brain barrier in claudin-5-deficient mice," Journal of Cell Biology, vol. 161, no. 3, pp. 653-660, 2003.

[5] M. Lioni, P. Brafford, C. Andl et al., "Dysregulation of claudin-7 leads to loss of E-cadherin expression and the increased invasion of esophageal squamous cell carcinoma cells," American Journal of Pathology, vol. 170, no. 2, pp. 709721, 2007.
[6] P. Dhawan, A. B. Singh, N. G. Deane et al., "Claudin-1 regulates cellular transformation and metastatic behavior in colon cancer," Journal of Clinical Investigation, vol. 115, no. 7, pp. 1765-1776, 2005.

[7] X. Y. Pan, B. Wang, Y. C. Che, Z. P. Weng, H. Y. Dai, and W. Peng, "Expression of claudin-3 and claudin-4 in normal, hyperplastic, and malignant endometrial tissue," International Journal of Gynecological Cancer, vol. 17, no. 1, pp. 233-241, 2007.

[8] M. Nita-Lazar, I. Rebustini, J. Walker, and M. A. Kukuruzinska, "Hypoglycosylated E-cadherin promotes the assembly of tight junctions through the recruitment of PP2A to adherens junctions," Experimental Cell Research, vol. 316, no. 11, pp. 1871-1884, 2010.

[9] A. B. Singh, A. Sharma, and P. Dhawan, "Claudin family of proteins and cancer: an overview," Jounral of Oncology, vol. 2010, p. 11, 2010.

[10] E. Delva, D. K. Tucker, and A. P. Kowalczyk, "The desmosome," Cold Spring Harbor Perspectives in Biology, vol. 1, no. 2, Article ID a002543, 2009.

[11] L. M. Godsel, S. Getsios, A. C. Huen, and K. J. Green, "The molecular composition and function of desmosomes," Handbook of Experimental Pharmacology, pp. 137-193, 2004.

[12] R. B. Troyanovsky, N. A. Chitaev, and S. M. Troyanovsky, "Cadherin binding sites of plakoglobin: localization, specificity and role in targeting to adhering junctions," Journal of Cell Science, vol. 109, no. 13, pp. 3069-3078, 1996.

[13] J. K. Wahl, P. A. Sacco, T. M. McGranahan-Sadler, L. M. Sauppé, M. J. Wheelock, and K. R. Johnson, "Plakoglobin domains that define its association with the desmosomal cadherins and the classical cadherins: identification of unique and shared domains," Journal of Cell Science, vol. 109, no. 5, pp. 1143-1154, 1996.

[14] P. Cowin, H.-P. Kapprell, W. W. Franke, J. Tamkun, and R. O. Hynes, "Plakoglobin: a protein common to different kinds of intercellular adhering junctions," Cell, vol. 46, no. 7, pp. 1063-1073, 1986.

[15] D. Salomon, O. Ayalon, R. Patel-King, R. O. Hynes, and B. Geiger, "Extrajunctional distribution of N-cadherin in cultured human endothelial cells," Journal of Cell Science, vol. 102, no. 1, pp. 7-17, 1992.

[16] S. Miravet, J. Piedra, F. Miró, E. Itarte, A. Garcia de Herreros, and M. Duñach, "The transcriptional factor Tcf- 4 contains different binding sites for $\beta$-catenin and plakoglobin," Journal of Biological Chemistry, vol. 277, no. 3, pp. 1884-1891, 2002.

[17] O. Maeda, N. Usami, M. Kondo et al., "Plakoglobin ( $\gamma$-catenin) has TCF/LEF family-dependent transcriptional activity in $\beta$-catenin-deficient cell line," Oncogene, vol. 23, no. 4, pp. 964-972, 2004.

[18] J. Depondt, E.-H. Shabana, F. Walker, L. Pibouin, F. Lezot, and A. Berdal, "Nasal inverted papilloma expresses the muscle segment homeobox gene Msx2: possible prognostic implications," Human Pathology, vol. 39, no. 3, pp. 350-358, 2008.

[19] H. Pang, B. G. Rowan, M. Al-Dhaheri, and L. E. Faber, "Epidermal growth factor suppresses induction by progestin of the adhesion protein desmoplakin in T47D breast cancer cells," Breast Cancer Research, vol. 6, no. 3, pp. R239-R245, 2004.

[20] X. Zhou, A. Stuart, L. E. Dettin, G. Rodriguez, B. Hoel, and G. I. Gallicano, "Desmoplakin is required for microvascular tube formation in culture," Journal of Cell Science, vol. 117, no. 15, pp. 3129-3140, 2004. 
[21] J. R. Stanley, "Autoantibodies against adhesion molecules and structures in blistering skin diseases," Journal of Experimental Medicine, vol. 181, no. 1, pp. 1-4, 1995.

[22] J. Waschke, V. Spindler, P. Bruggeman, D. Zillikens, G. Schmidt, and D. Drenckhahn, "Inhibition of Rho A activity causes pemphigus skin blistering," Journal of Cell Biology, vol. 175, no. 5, pp. 721-727, 2006.

[23] L. Eshkind, Q. Tian, A. Schmidt, W. W. Franke, R. Windoffer, and R. E. Leube, "Loss of desmoglein 2 suggests essential functions for early embryonic development and proliferation of embryonal stem cells," European Journal of Cell Biology, vol. 81, no. 11, pp. 592-598, 2002.

[24] P. J. Koch, M. G. Mahoney, H. Ishikawa et al., "Targeted disruption of the pemphigus vulgaris antigen (desmoglein 3 ) gene in mice causes loss of keratinocyte cell adhesion with a phenotype similar to pemphigus vulgaris," Journal of Cell Biology, vol. 137, no. 5, pp. 1091-1102, 1997.

[25] L. Pulkkinen, Y. W. Choi, A. Simpson et al., "Loss of cell adhesion in Dsg3bal-Pas mice with homozygous deletion mutation (2079del14) in the desmoglein 3 gene," Journal of Investigative Dermatology, vol. 119, no. 6, pp. 1237-1243, 2002.

[26] C. Bierkamp, K. J. McLaughlin, H. Schwarz, O. Huber, and R. Kemler, "Embryonic heart and skin defects in mice lacking plakoglobin,” Developmental Biology, vol. 180, no. 2, pp. 780785, 1996.

[27] V. Vasioukhin, E. Bowers, C. Bauer, L. Degenstein, and E. Fuchs, "Desmoplakin is essential in epidermal sheet formation," Nature Cell Biology, vol. 3, no. 12, pp. 1076-1085, 2001.

[28] M. P. Wong, M. Cheang, E. Yorida et al., "Loss of desmoglein 1 expression associated with worse prognosis in head and neck squamous cell carcinoma patients," Pathology, vol. 40, no. 6, pp. 611-616, 2008.

[29] D. Brennan and M. G. Mahoney, "Increased expression of Dsg2 in malignant skin carcinomas: a tissue-microarray based study," Cell Adhesion and Migration, vol. 3, no. 2, pp. 148-154, 2009.

[30] A. E. Bass-Zubek, L. M. Godsel, M. Delmar, and K. J. Green, "Plakophilins: multifunctional scaffolds for adhesion and signaling," Current Opinion in Cell Biology, vol. 21, no. 5, pp. 708-716, 2009.

[31] A. P. South, H. Wan, M. G. Stone et al., "Lack of plakophilin 1 increases keratinocyte migration and reduces desmosome stability," Journal of Cell Science, vol. 116, no. 16, pp. 33033314, 2003.

[32] T. Sobolik-Delmaire, D. Katafiasz, S. A. Keim, M. G. Mahoney, and J. K. Wahl III, "Decreased plakophilin-1 expression promotes increased motility in head and neck squamous cell carcinoma cells," Cell Communication and Adhesion, vol. 14, no. 2-3, pp. 99-109, 2007.

[33] S. T. Kundu, P. Gosavi, N. Khapare et al., "Plakophilin3 downregulation leads to a decrease in cell adhesion and promotes metastasis," International Journal of Cancer, vol. 123, no. 10, pp. 2303-2314, 2008.

[34] S. Pieperhoff, M. Barth, S. Rickelt, and W. W. Franke, "Desmosomal molecules in and out of adhering junctions: normal and diseased States of epidermal, cardiac and mesenchymally derived cells," Dermatology Research and Practice, vol. 2010, Article ID 139167, 12 pages, 2010.

[35] S. Pieperhoff, C. Borrmann, C. Grund, M. Barth, S. Rizzo, and W. W. Franke, "The area composita of adhering junctions connecting heart muscle cells of vertebrates. VII. The different types of lateral junctions between the special cardiomyocytes of the conduction system of ovine and bovine hearts," European Journal of Cell Biology, vol. 89, no. 5, pp. 365-378, 2010.

[36] L. Larue, M. Ohsugi, J. Hirchenhain, and R. Kemler, "Ecadherin null mutant embryos fail to form a trophectoderm epithelium," Proceedings of the National Academy of Sciences of the United States of America, vol. 91, no. 17, pp. 8263-8267, 1994.

[37] H. Haegel, L. Larue, M. Ohsugi, L. Fedorov, K. Herrenknecht, and R. Kemler, "Lack of $\beta$-catenin affects mouse development at gastrulation," Development, vol. 121, no. 11, pp. 35293537, 1995.

[38] G. L. Radice, H. Rayburn, H. Matsunami, K. A. Knudsen, M. Takeichi, and R. O. Hynes, "Developmental defects in mouse embryos lacking N-cadherin," Developmental Biology, vol. 181, no. 1, pp. 64-78, 1997.

[39] D. Vittet, T. Buchou, A. Schweitzer, E. Dejana, and P. Huber, "Targeted null-mutation in the vascular endothelial-cadherin gene impairs the organization of vascular-like structures in embryoid bodies," Proceedings of the National Academy of Sciences of the United States of America, vol. 94, no. 12, pp. 6273-6278, 1997.

[40] P. Young, O. Boussadia, H. Halfter et al., "E-cadherin controls adherens junctions in the epidermis and the renewal of hair follicles," EMBO Journal, vol. 22, no. 21, pp. 5723-5733, 2003.

[41] G. Calì, M. Zannini, P. Rubini et al., "Conditional inactivation of the E-cadherin gene in thyroid follicular cells affects gland development but does not impair junction formation," Endocrinology, vol. 148, no. 6, pp. 2737-2746, 2007.

[42] C. L. Tinkle, T. Lechler, H. A. Pasolli, and E. Fuchs, "Conditional targeting of E-cadherin in skin: insights into hyperproliferative and degenerative responses," Proceedings of the National Academy of Sciences of the United States of America, vol. 101, no. 2, pp. 552-557, 2004.

[43] T. T. Onder, P. B. Gupta, S. A. Mani, J. Yang, E. S. Lander, and R. A. Weinberg, "Loss of E-cadherin promotes metastasis via multiple downstream transcriptional pathways," Cancer Research, vol. 68, no. 10, pp. 3645-3654, 2008.

[44] Y. Kam and V. Quaranta, "Cadherin-bound $\beta$-catenin feeds into the Wnt pathway upon adherens junctions dissociation: evidence for an intersection between $\beta$-catenin pools," PLoS ONE, vol. 4, no. 2, article e4580, 2009.

[45] A. S. T. Wong and B. M. Gumbiner, "Adhesion-independent mechanism for suppression of tumor cell invasion by Ecadherin," Journal of Cell Biology, vol. 161, no. 6, pp. 11911203, 2003.

[46] K. Strumane, G. Berx, and F. van Roy, "Cadherins in cancer," Handbook of Experimental Pharmacology, pp. 69-103, 2004.

[47] M. Mareel, K. Vleminckx, S. Vermeulen, G. Yan, M. Bracke, and F. van Roy, "Downregulation in vivo of the invasionsuppressor molecule E-cadherin in experimental and clinical cancer," Princess Takamatsu Symposia, vol. 24, pp. 63-80, 1994.

[48] Y. Kanai, T. Oda, Y. Shimoyama et al., "Alterations of the cadherin-catenin cell adhesion system in cancers," Princess Takamatsu Symposia, vol. 24, pp. 51-62, 1994.

[49] S. Tsukita, S. Tsukita, A. Nagafuchi, and S. Yonemura, "Possible involvement of adherens junction plaque proteins in tumorigenesis and metastasis," Princess Takamatsu Symposia, vol. 24, pp. 38-50, 1994.

[50] J. Stappert and R. Kemler, "A short core region of E-cadherin is essential for catenin binding and is highly phosphorylated," Cell Adhesion and Communication, vol. 2, no. 4, pp. 319-327, 1994. 
[51] M. A. Thoreson, P. Z. Anastasiadis, J. M. Daniel et al., "Selective uncoupling of p120(ctn) from E-cadherin disrupts strong adhesion," Journal of Cell Biology, vol. 148, no. 1, pp. 189-201, 2000.

[52] N. Rudini and E. Dejana, "Adherens junctions," Current Biology, vol. 18, no. 23, pp. R1080-R1082, 2008.

[53] C. J. Gottardi and B. M. Gumbiner, "Distinct molecular forms of $\beta$-catenin are targeted to adhesive or transcriptional complexes," Journal of Cell Biology, vol. 167, no. 2, pp. 339349, 2004.

[54] H. Clevers, "Wnt/ $\beta$-catenin signaling in development and disease," Cell, vol. 127, no. 3, pp. 469-480, 2006.

[55] J. Behrens, "Control of $\beta$-catenin signaling in tumor development," Annals of the New York Academy of Sciences, vol. 910, pp. 21-35, 2000.

[56] V. J. M. Wielenga, R. Smits, V. Korinek et al., "Expression of CD44 in Apc and Tcf mutant mice implies regulation by the WNT pathway," American Journal of Pathology, vol. 154, no. 2, pp. 515-523, 1999.

[57] R. Fodde and T. Brabletz, "Wnt/ $\beta$-catenin signaling in cancer stemness and malignant behavior," Current Opinion in Cell Biology, vol. 19, no. 2, pp. 150-158, 2007.

[58] J. Schneikert and J. Behrens, "The canonical Wnt signalling pathway and its APC partner in colon cancer development," Gut, vol. 56, no. 3, pp. 417-425, 2007.

[59] J. M. Daniel and A. B. Reynolds, "The catenin p120(ctn) interacts with Kaiso, a novel BTB/POZ domain zinc finger transcription factor," Molecular and Cellular Biology, vol. 19, no. 5, pp. 3614-3623, 1999.

[60] J.-I. Park, H. Ji, S. Jun et al., "Frodo links dishevelled to the p120-catenin/Kaiso pathway: distinct catenin subfamilies promote Wnt signals," Developmental Cell, vol. 11, no. 5, pp. 683-695, 2006.

[61] J.-I. Park, S. W. Kim, J. P. Lyons et al., "Kaiso/p120catenin and TCF/ $\beta$-catenin complexes coordinately regulate canonical Wnt gene targets," Developmental Cell, vol. 8, no. 6, pp. 843-854, 2005.

[62] S. W. Kim, J.-I. Park, C. M. Spring et al., "Non-canonical Wnt signals are modulated by the Kaiso transcriptional repressor and p120-catenin," Nature Cell Biology, vol. 6, no. 12, pp. 1212-1220, 2004.

[63] P. Z. Anastasiadis, "p120-ctn: a nexus for contextual signaling via Rho GTPases," Biochimica et Biophysica Acta, vol. 1773, no. 1, pp. 34-46, 2007.

[64] G. A. Wildenberg, M. R. Dohn, R. H. Carnahan et al., "p120-catenin and p190RhoGAP regulate cell-cell adhesion by coordinating antagonism between Rac and Rho," Cell, vol. 127, no. 5, pp. 1027-1039, 2006.

[65] M. Yanagisawa, D. Huveldt, P. Kreinest et al., "A p120 catenin isoform switch affects rho activity, induces tumor cell invasion, and predicts metastatic disease," Journal of Biological Chemistry, vol. 283, no. 26, pp. 18344-18354, 2008.

[66] L. W. T. Cheung, P. C. K. Leung, and A. S. T. Wong, "Cadherin switching and activation of p120 catenin signaling are mediators of gonadotropin-releasing hormone to promote tumor cell migration and invasion in ovarian cancer," Oncogene, vol. 29, no. 16, pp. 2427-2440, 2010.

[67] N. T. Chartier, C. I. Oddou, M. G. Lainé et al., "Cyclindependent kinase 2/cyclin E complex is involved in p120 catenin (p120ctn)-dependent cell growth control: a new role for p120ctn in cancer," Cancer Research, vol. 67, no. 20, pp. 9781-9790, 2007.
[68] M. Perez-Moreno, W. Song, H. A. Pasolli, S. E. Williams, and E. Fuchs, "Loss of p120 catenin and links to mitotic alterations, inflammation, and skin cancer," Proceedings of the National Academy of Sciences of the United States of America, vol. 105, no. 40, pp. 15399-15404, 2008.

[69] W. G. Smalley-Freed, A. Efimov, P. E. Burnett et al., "p120catenin is essential for maintenance of barrier function and intestinal homeostasis in mice," Journal of Clinical Investigation, vol. 120, no. 6, pp. 1824-1835, 2010.

[70] D. M. Bryant, F. G. Wylie, and J. L. Stow, "Regulation of endocytosis, nuclear translocation, and signaling of fibroblast growth factor receptor 1 by E-cadherin," Molecular Biology of the Cell, vol. 16, no. 1, pp. 14-23, 2005.

[71] R. B. Hazan, R. Qiao, R. Keren, I. Badano, and K. Suyama, "Cadherin switch in tumor progression," Annals of the New York Academy of Sciences, vol. 1014, pp. 155-163, 2004.

[72] M. J. Wheelock, Y. Shintani, M. Maeda, Y. Fukumoto, and K. R. Johnson, "Cadherin switching," Journal of Cell Science, vol. 121, no. 6, pp. 727-735, 2008.

[73] S. Pece and J. S. Gutkind, "Signaling from E-cadharins to the MAPK pathway by the recruitment and activation of epidermal growth factor receptors upon cell-cell contact formation," Journal of Biological Chemistry, vol. 275, no. 52, pp. 41227-41233, 2000.

[74] H. Hoschuetzky, H. Aberle, and R. Kemler, " $\beta$-catenin mediates the interaction of the cadherin-catenin complex with epidermal growth factor receptor," Journal of Cell Biology, vol. 127, no. 5, pp. 1375-1380, 1994.

[75] A. Bremm, A. Walch, M. Fuchs et al., "Enhanced activation of epidermal growth factor receptor caused by tumor-derived E-cadherin mutations," Cancer Research, vol. 68, no. 3, pp. 707-714, 2008.

[76] G. Berx, A.-M. Cleton-Jansen, F. Nollet et al., "E-cadherin is a tumour/invasion suppressor gene mutated in human lobular breast cancers," EMBO Journal, vol. 14, no. 24, pp. 61076115, 1995.

[77] M. Perrais, X. Chen, M. Perez-Moreno, and B. M. Gumbiner, "E-cadherin homophilic ligation inhibits cell growth and epidermal growth factor receptor signaling independently of other cell interactions," Molecular Biology of the Cell, vol. 18, no. 6, pp. 2013-2025, 2007.

[78] X. Qian, T. Karpova, A. M. Sheppard, J. McNally, and D. R. Lowy, "E-cadherin-mediated adhesion inhibits liganddependent activation of diverse receptor tyrosine kinases," EMBO Journal, vol. 23, no. 8, pp. 1739-1748, 2004.

[79] S. Getsios, C. L. Simpson, S.-I. Kojima et al., "Desmoglein 1-dependent suppression of EGFR signaling promotes epidermal differentiation and morphogenesis," Journal of Cell Biology, vol. 185, no. 7, pp. 1243-1258, 2009.

[80] E. Dejana, "Endothelial cell-cell junctions: happy together," Nature Reviews Molecular Cell Biology, vol. 5, no. 4, pp. 261270, 2004.

[81] M. G. Lampugnani, F. Orsenigo, M. C. Gagliani, C. Tacchetti, and E. Dejana, "Vascular endothelial cadherin controls VEGFR-2 internalization and signaling from intracellular compartments," Journal of Cell Biology, vol. 174, no. 4, pp. 593-604, 2006.

[82] N. Rudini, A. Felici, C. Giampietro et al., "VE-cadherin is a critical endothelial regulator of TGF- $\beta$ signalling," EMBO Journal, vol. 27, no. 7, pp. 993-1004, 2008.

[83] S. Liebner, A. Cattelino, R. Gallini et al., " $\beta$-catenin is required for endothelial-mesenchymal transformation during heart cushion development in the mouse," Journal of Cell Biology, vol. 166, no. 3, pp. 359-367, 2004. 
[84] L.-W. Qian, W. Greene, F. Ye, and S.-J. Gao, "Kaposi's sarcoma-associated herpesvirus disrupts adherens junctions and increases endothelial permeability by inducing degradation of VE-cadherin," Journal of Virology, vol. 82, no. 23, pp. 11902-11912, 2008.

[85] E. Lara-Pezzi, S. Roche, O. M. Andrisani, F. Sánchez-Madrid, and M. López-Cabrera, "The hepatitis B virus HBx protein induces adherens junction disruption in a src-dependent manner," Oncogene, vol. 20, no. 26, pp. 3323-3331, 2001.

[86] S. Niemhom, S. Kitazawa, R. Kitazawa, S. Maeda, and J. Leopairat, "Hypermethylation of epithelial-cadherin gene promoter is associated with Epstein-Barr virus in nasopharyngeal carcinoma," Cancer Detection and Prevention, vol. 32, no. 2, pp. 127-134, 2008.

[87] J. Laurson, S. Khan, R. Chung, K. Cross, and K. Raj, "Epigenetic repression of E-cadherin by human papillomavirus 16 E7 protein," Carcinogenesis, vol. 31, no. 5, pp. 918-926, 2010.

[88] K. Hellner, J. Mar, F. Fang, J. Quackenbush, and K. Münger, "HPV16 E7 oncogene expression in normal human epithelial cells causes molecular changes indicative of an epithelial to mesenchymal transition," Virology, vol. 391, no. 1, pp. 57-63, 2009.

[89] J. Wilding, K. H. Vousden, W. P. Soutter, P. D. McCrea, R. Del Buono, and M. Pignatelli, "E-cadherin transfection down-regulates the epidermal growth factor receptor and reverses the invasive phenotype of human papilloma virustransfected keratinocytes," Cancer Research, vol. 56, no. 22, pp. 5285-5292, 1996.

[90] A.-E. Al Moustafa, A. Kassab, A. Darnel, and A. Yasmeen, "High-risk HPV/ErbB-2 interaction on E-cadherin/catenin regulation in human carcinogenesis," Current Pharmaceutical Design, vol. 14, no. 22, pp. 2159-2172, 2008.

[91] A. Yasmeen, A. Alachkar, H. Dekhil, C. GambacortiPasserini, and A. E. Al Moustafa, "Locking Src/Abl tyrosine kinase activities regulate cell differentiation and invasion of human cervical cancer cells expressing E6/E7 oncoproteins of high-risk HPV," Jounral of Oncology, vol. 2010, p. 10, 2010.

[92] K. H. Y. Shair, C. I. Schnegg, and N. Raab-Traub, "EpsteinBarr virus latent membrane protein-1 effects on junctional plakoglobin and induction of a cadherin switch," Cancer Research, vol. 69, no. 14, pp. 5734-5742, 2009.

[93] O. Schmalhofer, S. Brabletz, and T. Brabletz, "E-cadherin, $\beta$-catenin, and ZEB1 in malignant progression of cancer," Cancer and Metastasis Reviews, vol. 28, no. 1-2, pp. 151-166, 2009.

[94] U. Tepass, K. Truong, D. Godt, M. Ikura, and M. Peifer, "Cadherins in embryonic and neural morphogenesis," Nature Reviews Molecular Cell Biology, vol. 1, no. 2, pp. 91-100, 2000.

[95] L. Larue and A. Bellacosa, "Epithelial-mesenchymal transition in development and cancer: role of phosphatidylinositol 3' kinase/AKT pathways," Oncogene, vol. 24, no. 50, pp. 7443-7454, 2005.

[96] J. P. Their, "Epithelial-mesenchymal transitions in tumor progression," Nature Reviews Cancer, vol. 2, no. 6, pp. 442454, 2002.

[97] P. J. Miettinen, R. Ebner, A. R. Lopez, and R. Derynck, “TGF$\beta$ induced transdifferentiation of mammary epithelial cells to mesenchymal cells: involvement of type I receptors," Journal of Cell Biology, vol. 127, no. 6, pp. 2021-2036, 1994.

[98] M. Oft, K.-H. Heider, and H. Beug, "TGF $\beta$ signaling is necessary for carcinoma cell invasiveness and metastasis," Current Biology, vol. 8, no. 23, pp. 1243-1252, 1998.
[99] M. Oft, J. Peli, C. Rudaz, H. Schwarz, H. Beug, and E. Reichmann, "TGF- $\beta 1$ and Ha-Ras collaborate in modulating the phenotypic plasticity and invasiveness of epithelial tumor cells," Genes and Development, vol. 10, no. 19, pp. 2462-2477, 1996.

[100] G. Portella, S. A. Cumming, J. Liddell et al., “Transforming growth factor $\beta$ is essential for spindle cell conversion of mouse skin carcinoma in vivo: implications for tumor invasion," Cell Growth and Differentiation, vol. 9, no. 5, pp. 393-404, 1998.

[101] N. A. Bhowmick, M. Ghiassi, A. Bakin et al., "Transforming growth factor- $\beta 1$ mediates epithelial to mesenchymal transdifferentiation through a RhoA-dependent mechanism," Molecular Biology of the Cell, vol. 12, no. 1, pp. 27-36, 2001.

[102] E. Piek, A. Moustakas, A. Kurisaki, C.-H. Heldin, and P. ten Dijke, "TGF- $\beta$ type I receptor/ALK-5 and Smad proteins mediate epithelial to mesenchymal transdifferentiation in NMuMG breast epithelial cells," Journal of Cell Science, vol. 112, no. 24, pp. 4557-4568, 1999.

[103] B. Deng, X. Yang, J. Liu, F. He, Z. Zhu, and C. Zhang, "Focal adhesion kinase mediates TGF- $\beta 1$-induced renal tubular epithelial-to-mesenchymal transition in vitro," Molecular and Cellular Biochemistry, vol. 340, no. 1-2, pp. 21-29, 2010.

[104] J. Zhong, A. Paul, S. J. Kellie, and G. M. O'Neill, "Mesenchymal migration as a therapeutic target in glioblastoma," Jounral of Oncology, vol. 2010, p. 17, 2010.

[105] J. Chunthapong, E. A. Seftor, Z. Khalkhali-Ellis et al., "Dual roles of E-cadherin in prostate cancer invasion," Journal of Cellular Biochemistry, vol. 91, no. 4, pp. 649-661, 2004.

[106] C. C. Lynch, T. Vargo-Gogola, L. M. Matrisian, and B. Fingleton, "Cleavage of e-cadherin by matrix metalloproteinase-7 promotes cellular proliferation in nontransformed cell lines via activation of RhoA," Jounral of Oncology, vol. 2010, p. 11, 2010.

[107] S. H. Ngalim, A. Magenau, G. Le Saux, J. J. Gooding, and K. Gaus, "How do cells make decisions: engineering micro- and nanoenvironments for cell migration," Jounral of Oncology, vol. 2010, p. 7, 2010.

[108] S. Josson, S. Sharp, S. Y. Sung et al., "Tumor-stromal interactions influence radiation sensitivity in epithelial- versus mesenchymal-like prostate cancer cells," Jounral of Oncology, vol. 2010, p. 10, 2010.

[109] H. Yamashita, M. Tripathi, J. Jourquin et al., "Lysophosphatidic acid upregulates laminin-332 expression during A431 cell colony dispersal," Jounral of Oncology, vol. 2010, p. 8, 2010.

[110] L. Ma, J. Young, H. Prabhala et al., "MiR-9, a MYC/MYCNactivated microRNA, regulates E-cadherin and cancer metastasis," Nature Cell Biology, vol. 12, no. 3, pp. 247-256, 2010.

[111] M. Sachdeva and Y.-Y. Mo, "MicroRNA-145 suppresses cell invasion and metastasis by directly targeting mucin 1," Cancer Research, vol. 70, no. 1, pp. 378-387, 2010.

[112] V. Gabarra-Niecko, M. D. Schaller, and J. M. Dunty, "FAK regulates biological processes important for the pathogenesis of cancer," Cancer and Metastasis Reviews, vol. 22, no. 4, pp. 359-374, 2003.

[113] T. P. Hecker and C. L. Gladson, "Focal adhesion kinase in cancer," Frontiers in Bioscience, vol. 8, pp. s705-s714, 2003.

[114] M. Canel, P. Secades, J.-P. Rodrigo et al., "Overexpression of focal adhesion kinase in head and neck squamous cell carcinoma is independent of fak gene copy number," Clinical Cancer Research, vol. 12, no. 11 I, pp. 3272-3279, 2006. 
[115] S. K. Hanks, L. Ryzhova, N.-Y. Shin, and J. Brábek, "Focal adhesion kinase signaling activities and their implications in the control of cell survival and motility," Frontiers in Bioscience, vol. 8, pp. d982-d996, 2003.

[116] J. T. Parsons, "Focal adhesion kinase: the first ten years," Journal of Cell Science, vol. 116, no. 8, pp. 1409-1416, 2003.

[117] D. Ilic, Y. Furuta, S. Kanazawa et al., "Reduced cell motility and enhanced focal adhesion contact formation in cells from FAK-deficient mice," Nature, vol. 377, no. 6549, pp. 539-544, 1995.

[118] J. D. Owen, P. J. Ruest, D. W. Fry, and S. K. Hanks, "Induced focal adhesion kinase (FAK) expression in FAKnull cells enhances cell spreading and migration requiring both auto- and activation loop phosphorylation sites and inhibits adhesion-dependent tyrosine phosphorylation of Pyk2," Molecular and Cellular Biology, vol. 19, no. 7, pp. 4806-4818, 1999.

[119] M. Raftopoulou and A. Hall, "Cell migration: Rho GTPases lead the way," Developmental Biology, vol. 265, no. 1, pp. 23$32,2004$.

[120] A. Hamadi, T. B. Deramaudt, K. Takeda, and P. Rondé, "Hyperphosphorylated FAK delocalizes from focal adhesions to membrane ruffles," Jounral of Oncology, vol. 2010, p. 10, 2010.

[121] H. Yano, Y. Mazaki, K. Kurokawa, S. K. Hanks, M. Matsuda, and H. Sabe, "Roles played by a subset of integrin signaling molecules in cadherin-based cell-cell adhesion," Journal of Cell Biology, vol. 166, no. 2, pp. 283-295, 2004.

[122] A. S. Yap and E. M. Kovacs, "Direct cadherin-activated cell signaling: a view from the plasma membrane," Journal of Cell Biology, vol. 160, no. 1, pp. 11-16, 2003.

[123] S. Charrasse, M. Meriane, F. Comunale, A. Blangy, and C. Gauthier-Rouvière, "N-cadherin-dependent cell-cell contact regulates Rho GTPases and $\beta$-catenin localization in mouse C2C12 myoblasts," Journal of Cell Biology, vol. 158, no. 5, pp. 953-965, 2002.

[124] V. M. Golubovskaya and W. Cance, "Focal adhesion kinase and p53 signal transduction pathways in cancer," Frontiers in Bioscience, vol. 15, pp. 901-912, 2010.

[125] T. Sakisaka and Y. Takai, "Biology and pathology of nectins and nectin-like molecules," Current Opinion in Cell Biology, vol. 16, no. 5, pp. 513-521, 2004.

[126] A. Yamada, K. Irie, A. Fukuhara, T. Ooshio, and Y. Takai, "Requirement of the actin cytoskeleton for the association of nectins with other cell adhesion molecules at adherens and tight junctions in MDCK cells," Genes to Cells, vol. 9, no. 9, pp. 843-855, 2004.

[127] H. Ogita, Y. Rikitake, J. Miyoshi, and Y. Takai, "Cell adhesion molecules nectins and associating proteins: implications for physiology and pathology," Proceedings of the Japan Academy $B$, vol. 86, no. 6, pp. 621-629, 2010.

[128] H. Ogita and Y. Takai, "Cross-talk among integrin, cadherin, and growth factor receptor: roles of nectin and nectin-like molecule," International Review of Cytology, vol. 265, pp. 154, 2008.

[129] T. Ooshio, R. Kobayashi, W. Ikeda et al., "Involvement of the interaction of afadin with ZO-1 in the formation of tight junctions in Madin-Darby canine kidney cells," Journal of Biological Chemistry, vol. 285, no. 7, pp. 5003-5012, 2010.

[130] T. Hoshino, T. Sakisaka, T. Baba, T. Yamada, T. Kimura, and Y. Takai, "Regulation of E-cadherin endocytosis by nectin through afadin, Rap1, and p120ctn," Journal of Biological Chemistry, vol. 280, no. 25, pp. 24095-24103, 2005.
[131] T. Hoshino, K. Shimizu, T. Honda et al., "A novel role of nectins in inhibition of the E-cadherin-induced activation of Rac and formation of cell-cell adherens junctions," Molecular Biology of the Cell, vol. 15, no. 3, pp. 1077-1088, 2004.

[132] T. Sato, N. Fujita, A. Yamada et al., "Regulation of the assembly and adhesion activity of E-cadherin by nectin and afadin for the formation of adherens junctions in MadinDarby canine kidney cells," Journal of Biological Chemistry, vol. 281, no. 8, pp. 5288-5299, 2006.

[133] H. Nakanishi and Y. Takai, "Roles of nectins in cell adhesion, migration and polarization," Biological Chemistry, vol. 385, no. 10, pp. 885-892, 2004.

[134] M. Matsuda, J. K. Yamashita, S. Tsukita, and M. Furuse, "abLIM3 is a novel component of adherens junctions with actin-binding activity," European Journal of Cell Biology, vol. 89, no. 11, pp. 807-816, 2010.

[135] D. Schreiner and J. A. Weiner, "Combinatorial homophilic interaction between $\gamma$-protocadherin multimers greatly expands the molecular diversity of cell adhesion," Proceedings of the National Academy of Sciences of the United States of America, vol. 107, pp. 14893-14898, 2010.

[136] M. Frank and R. Kemler, "Protocadherins," Current Opinion in Cell Biology, vol. 14, no. 5, pp. 557-562, 2002.

[137] A. P. LaFlamme SEK, Ed., Cell Junctions. Adhesion, Development and Disease, Wiley-VCH, GmbH, Weinheim, Germany, 2008.

[138] U. Cavallaro and G. Christofori, "Cell adhesion and signalling by cadherins and Ig-CAMs in cancer," Nature Reviews Cancer, vol. 4, no. 2, pp. 118-132, 2004. 


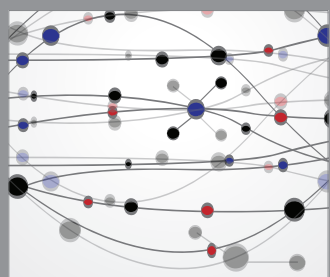

The Scientific World Journal
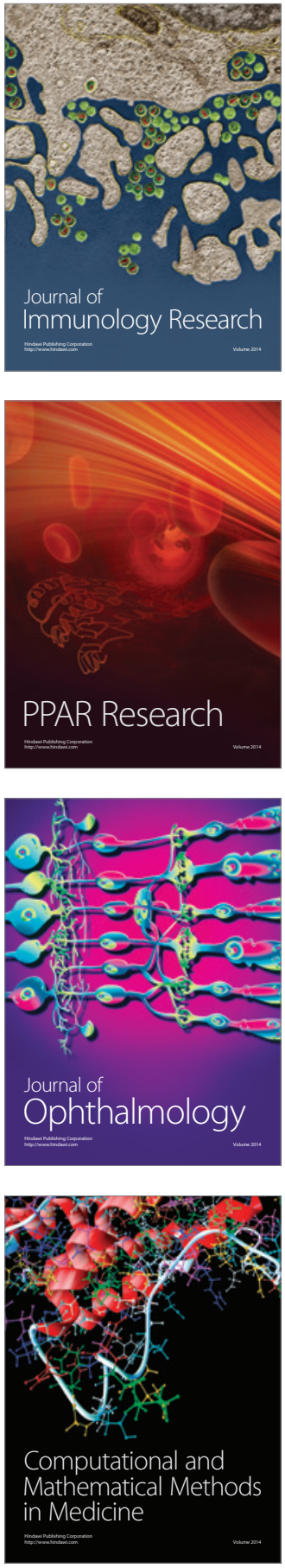

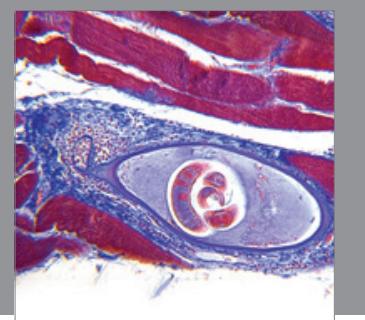

Gastroenterology

Research and Practice
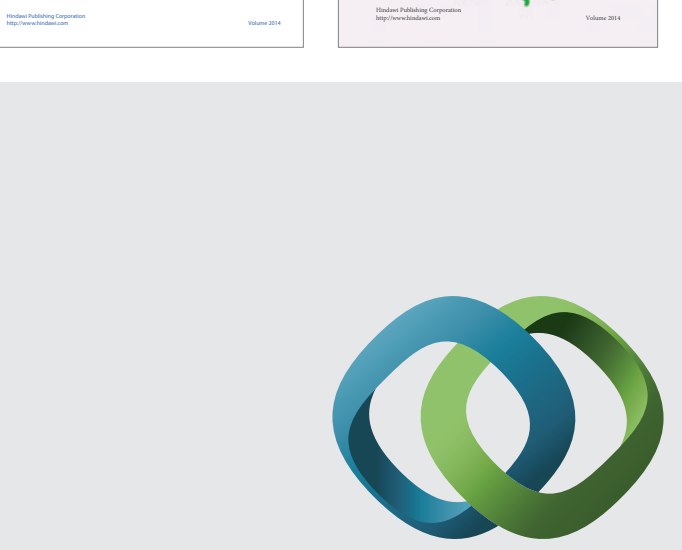

\section{Hindawi}

Submit your manuscripts at

http://www.hindawi.com
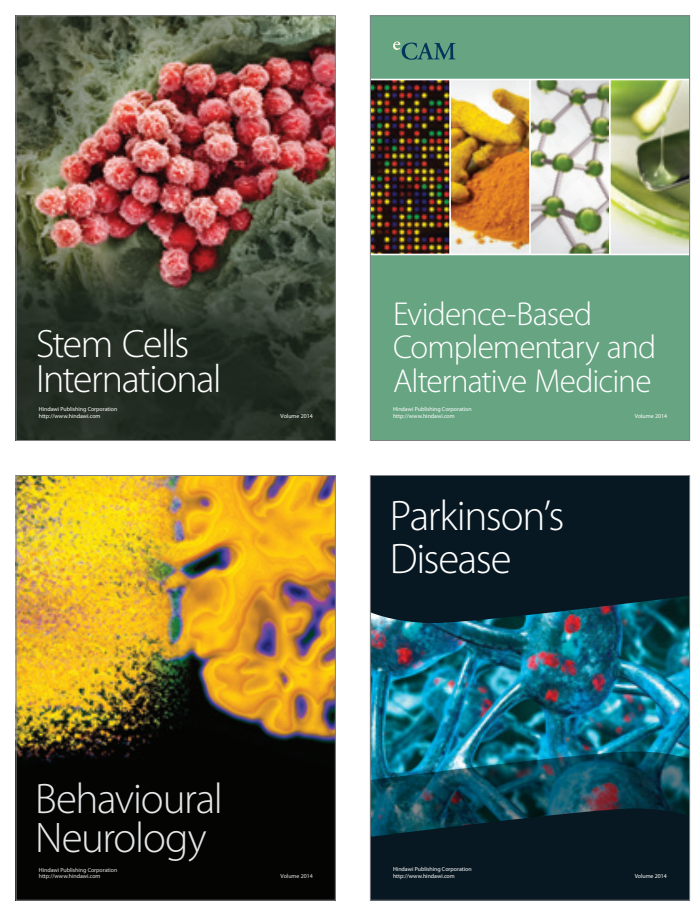

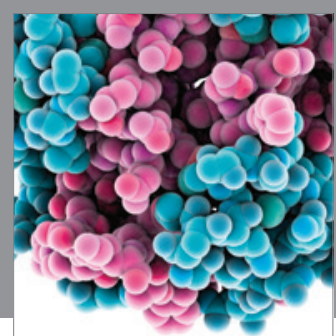

Journal of
Diabetes Research

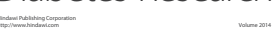

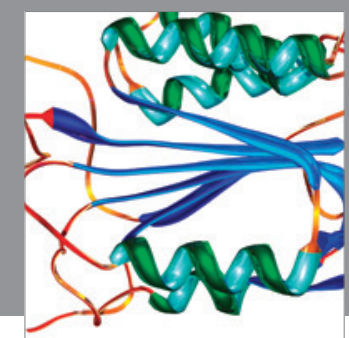

Disease Markers
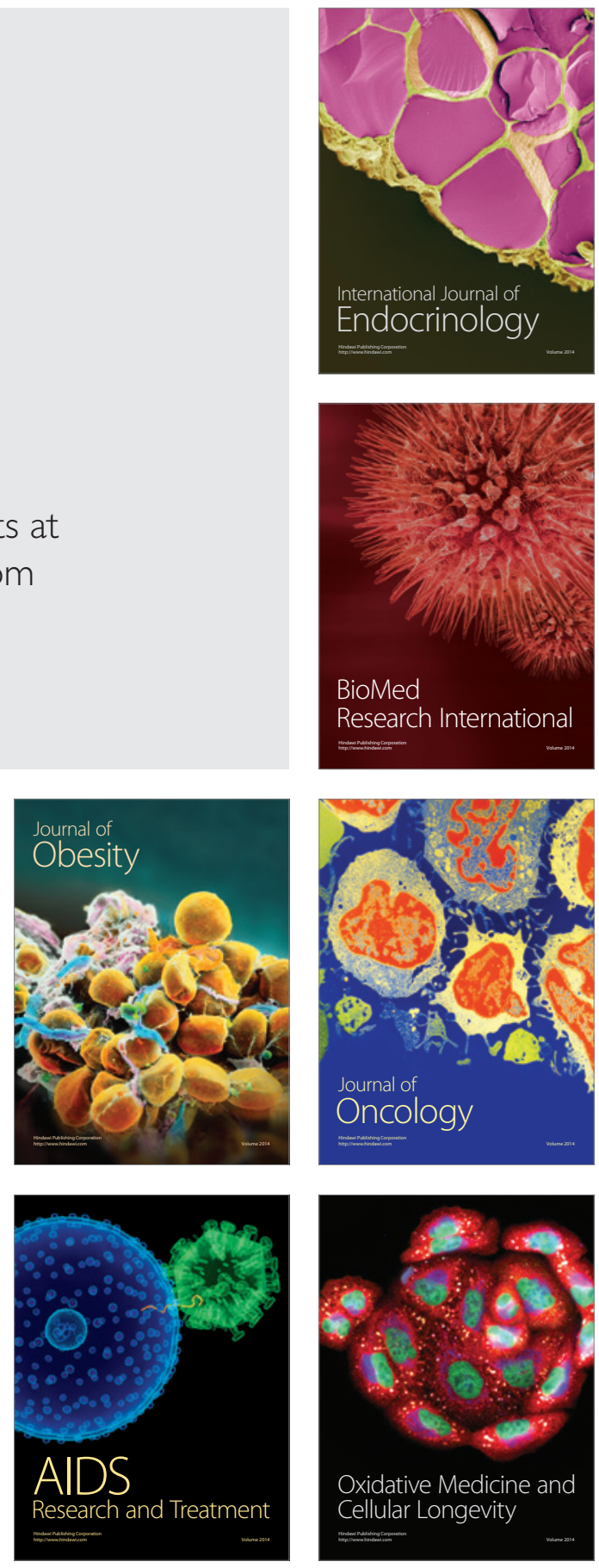